\title{
Frequent Words Improve Readability and Short Words Improve Understandability for People with Dyslexia
}

\author{
Luz Rello $^{1,2}$, Ricardo Baeza-Yates ${ }^{1,4}$, Laura Dempere-Marco ${ }^{3}$, and Horacio Saggion ${ }^{2}$ \\ ${ }^{1}$ Web Research Group, \\ ${ }^{2}$ Natural Language Processing Group, \\ ${ }^{3}$ Computational Neuroscience Group, Universitat Pompeu Fabra, Barcelona \\ ${ }^{4}$ Yahoo! Labs, Barcelona \\ \{luzrello, rbaeza\}@acm.org, \\ \{laura.dampere, horacio.saggion\}@upf.edu
}

\begin{abstract}
Around 10\% of the population has dyslexia, a reading disability that negatively affects a person's ability to read and comprehend texts. Previous work has studied how to optimize the text layout, but adapting the text content has not received that much attention. In this paper, we present an eye-tracking study that investigates if people with dyslexia would benefit from content simplification. In an experiment with 46 people, 23 with dyslexia and 23 as a control group, we compare texts where words were substituted by shorter/longer and more/less frequent synonyms. Using more frequent words caused the participants with dyslexia to read significantly faster, while the use of shorter words caused them to understand the text better. Amongst the control group, no significant effects were found. These results provide evidence that people with dyslexia may benefit from interactive tools that perform lexical simplification.
\end{abstract}

Keywords: Textual accessibility, dyslexia, eye-tracking, lexical simplification, readability, understandability, word frequency, word length.

\section{Introduction}

Dyslexia is a neurological reading disability that is characterized by difficulties with accurate and/or fluent word recognition and by poor spelling and decoding abilities [49]. Secondary consequences include problems in reading comprehension and reduced reading experience that can impede vocabulary growth and background knowledge [22]. Since a great amount of information is presented as text, this condition makes more difficult to people with dyslexia to use well standard information systems. According to the literature, people with dyslexia specifically encounter problems with less frequent words and long words [11, 20, 52].

The goal of this paper is to study to which extent word frequency and word length impacts text readability and understandability for native Spanish speakers with dyslexia. Readability refers to the legibility of a text, that is, the ease with which text can be read. Understandability refers to comprehensibility, that is, the ease with which text can be understood. Likewise to lexical simplification, which often involves 
replacing difficult words by their simpler synonyms [2], we replaced nouns by synonyms with diverse lengths and frequencies to study its effect on readability and understandability.

This research is motivated by (1) the social relevance of its results and, (2) the challenge of revealing whether people with dyslexia could benefit from lexical simplification tools, such as a browser plug-in which allows interactive substitution of complex words by simpler synonyms.

First, dyslexia is universal and frequent. Depending on the language, the estimation of the prevalence of dyslexia varies from 10-17.5\% for the population in the U.S.A. [21] to $8.6-11 \%$ for the Spanish speaking population $[7,23,36]$.

Dyslexia-related difficulties are also shared by other groups with special needs, such as people with low vision [16]. Moreover, symptoms of dyslexia are common to varying degrees among most people [12]. Another example of how research on dyslexia is useful for a broader public is the overlap of dyslexic-friendly recommendations with more general textual accessibility recommendations [29]. Hence, this investigation is extensible to general usability problems and to other target groups.

Second, given that dyslexia is a disability that affects language, we can assume that textual accessibility can be approached from two dimensions: form, i.e. customizing the text layout, and content, i.e. simplifying the text. Although there are applications that modify the text layout for users with dyslexia, such as Claro ScreenRuler Suite [8], SeeWord [17] or IDEAL e-Book reader [26], these only modify its design but not its content. Our experiments emulate possible lexical simplification strategies [2] and our results motivate the development of tools that simplify the textual content for people with dyslexia.

To the best of our knowledge, this is the first time that lexical complexity is measured in terms of readability and understandability for people with dyslexia using a methodology that combines eye-tracking and questionnaires. Therefore, this paper presents the following main contributions:

- A study about the effect of word frequency in readability and understandability, where the main result is that frequent words improve readability for people with dyslexia.

- A study about the effect of word length in readability and understandability, where the main result is that shorter words improve understandability for people with dyslexia.

- A comparison of both studies with a control group without dyslexia, where the effect of word length and frequency is not significant.

The rest of the paper is organized as follows. Section 2 covers related work while Section 3 presents the problem and the hypotheses of our research. Section 4 details the experimental methodology and Section 5 presents the results, which are subsequently discussed in Section 6. Finally, conclusions and future challenges are explained in Section 7. 


\section{Related Work}

Since readability strongly affects text comprehension, sometimes both terms have been used interchangeably. However, previous research with people with dyslexia have shown that both concepts need to be taken into consideration separately. For instance, in [35] comprehension has been found to be independent of readability for people with dyslexia, while text readability can be used as an indicator of comprehension for people without dyslexia. Hence, in this study we distinguish between readability and understandability. Notice also that in the definition of dyslexia reading abilities and reading comprehension are treated separately [22].

Most research in this area focus on English, but our study considers Spanish language. Dyslexia manifestations vary depending on different language orthographies [5]. Since English and Spanish have different orthographies findings from one language do not necessarily apply to the other language. In fact, English has a deep orthography where the relationships between letters and sounds are inconsistent and many exceptions are permitted. On the other hand, Spanish has a shallow orthography with a more regular alphabetic system that contains consistent mappings between letters and sounds, the second shallowest of European languages [45].

We chose to study word frequency and word length because they are related to the word's processing time [33, 44], and they are strongly related to the difficulties that people with dyslexia find $[11,20,52]$. Previous work related to our research can be divided into: (a) studies from experimental psychology about eye-movement of readers with dyslexia, (b) work about comprehension abilities of people with dyslexia, and (c) interfaces for people with dyslexia.

Eye-Movements of Readers with Dyslexia. There is an extensive body of knowledge about eye-movements of readers with dyslexia using eye-tracking. Most of these studies focus on finding ways to diagnose dyslexia. However, the nature of eyemovements of people with dyslexia is currently under debate. While some found differences [14] among the two populations, others did not [47]. The closest work to ours comes from experimental psychology [20], which studies the effect of word length and word frequency in relation with eye fixation patterns among readers. Their results show that low frequency and long words present longer gaze durations and more re-inspections. Their approach focuses on finding eye-movement patterns to study particular words with the aim to discard the oculomotor dysfunction hypothesis of dyslexia [20]. They analyze single words while we analyze the whole text.

Comprehension in People with Dyslexia. Previous research has studied the effect of long sentences with difficult structures [46], sentence context [30], and the incorporation of graphical schemes [39], among others, on text comprehension of readers with dyslexia. More related to our work are [46, 43] who have suggested that the text could be made more difficult by the inclusion of low frequency and long words.

Interfaces for People with Dyslexia. There are number of existing applications for people with dyslexia that alter the presentation of the text such as SeeWord ${ }^{1}$ [17],

${ }^{1}$ http: / / www . computing. dundee.ac.uk/projects/seeword/ 
Colour Explorer, ${ }^{2}$ Text4All ${ }^{3}$ [49], and Penfriend $X L{ }^{4}$ Other tools also incorporate text-to-speech technology such as Claro Screen Ruler Suite, ${ }^{5}$ or the IDEAL eBook reader $^{6}$ [26]. Dyseggxia ${ }^{7}$ [41] is a game for children with dyslexia that uses as a basis word modification, but, to the extent of our knowledge; there is no interface which modifies the text content to be read by people with dyslexia.

What is missing in previous research is knowledge about two factors of lexical complexity — word frequency and word length — in the Spanish language, and their impact on the reading performance and the comprehension of people with dyslexia, as well as the integration of these findings in tools for people with dyslexia.

\section{Word Frequency and Length in Dyslexia}

Among the language difficulties that people with dyslexia find, the additional difficulty that less frequent words (e.g. pristine) and longer words (e.g. prestidigitation) has been specially stressed $[11,20,52]$. The role of word frequency is so crucial in dyslexia that there is even a diagnosis of dyslexia based on the performance while reading frequent words [27].

Since word frequency and word length are naturally related in language, we studied them in two different experiments. The correlation originates from the fact that frequently used expressions tend to become shorter over time [24]. As stressed by Rayner et al. [33], to unveil cause and effect relationships, these dimensions have to be studied individually. Hence, our hypotheses are:

- H1.1: A larger number of high frequency words increases readability for people with dyslexia.

- H1.2: A larger number of high frequency words increases understandability for people with dyslexia.

- H2.1: The presence of short words compared to long words increases readability for people with dyslexia.

- H2.2: The presence of short words compared to long words increases understandability for people with dyslexia.

To the best of our knowledge, the rest of the dyslexia-related difficulties regarding words involve: irregular words ${ }^{8}$ [9], orthographic similar words, e.g. addition and audition [15], homophonic words or pseudo homophonic words, e.g. weather and

\footnotetext{
${ }^{2}$ http: / / colour-explorer.software.informer.com/9.0/

${ }^{3}$ http: / / www . text4all.net/

${ }^{4}$ http: //www.penfriend.biz/pf-xl.html

${ }^{5}$ http: / / www. clarosoftware. com/index.php?cPath=348

${ }^{6}$ https://play.google.com/store/apps / details?id=org. easyaccess .epubreader

${ }^{7}$ https: / / itunes.apple.com/es/app/dyseggxia/id534986729? mt =8

${ }^{8}$ Words in which there is no consistent correspondence between grapheme and phoneme, e.g. vase, pronounced as /vaz/.
} 
whether [31], foreign words [11], new words, e.g. fantabulous [11], words with errors [9], non-words, ${ }^{9}$ e.g. happisfaction [9], and numerical expressions [40]. In the experimental design we did not use words of such characteristics to control other possible effects.

\section{$4 \quad$ Methodology}

We study word frequency and word length as two independent variables in two different experiments. Nonetheless, the inherent relationship between frequency and length has constrained the selection criteria of the target words, i.e. long words are inevitably less frequent.

In the experiments, 46 participants ( 23 with dyslexia) had to read four texts, which were altered to include more/less frequent and longer/shorter words.

\subsection{Design}

For each experiment there were two conditions. In the first experiment, wordfrequency [ \pm frequent] served as independent variable with two levels: [+frequent] denotes the condition where suitable words were replaced by more frequent synonyms and [-frequent] denotes the condition where suitable words were replaced by less frequent synonyms. In the second experiment, word-length [ \pm long] served as independent variable with two levels: [-long] denotes the condition where suitable words were replaced by shorter synonyms and [+long] denotes the condition where suitable words were replaced by longer synonyms.

The experiments followed a within-subjects design, so every participant contributed to each of the conditions in both experiments. The order of conditions was counter-balanced to cancel out sequence effects. To measure readability and understandability, we consider reading time, eye fixations duration, and a comprehension score as dependent variables. Next, we explain them in detail.

Reading Time. Shorter reading durations are preferred to longer ones since faster reading is related to more readable texts [50]. Therefore, we use Reading Time, i.e. the time it takes for a participant to completely read one text, as a measure of readability. This measure is extracted from the eye-tracking data.

Fixation Duration. When reading a text, the eye does not move contiguously over text, but alternates saccades and visual fixations, that is, jumps in short steps and rests on parts of the text. Fixation duration denotes how long the eye rests still on a single place of the text. Fixation duration has been shown to be a valid indicator of readability. According to $[25,33,43]$, shorter fixations are associated with better readability while longer fixations can indicate that processing loads are greater.

Hence, we use fixation duration as a readability measure in addition to the reading time.

\footnotetext{
${ }^{9}$ A non-word is a word that has no meaning, is not known to exist, or is disapproved.
} 
Comprehension Score. To measure text comprehension we used inferential items, that is, questions that require a deep understanding of the content of the text. We used multiple-choice questions with three possible choices, one correct choice, one partially correct choice, and one wrong choice. To compute the text comprehension score, the choices counted $100 \%, 50 \%$, and $0 \%$, respectively.

\subsection{Design}

We had 23 Spanish speakers (12 female, 11 male) with a confirmed diagnosis of dyslexia (group D) that participated in our study. They were asked to bring their diagnoses to the experiment, to guarantee that dyslexia was diagnosed in an authorised centre or hospital. Their ages ranged from 13 to 37 , with a mean age of 20.74 years ( $s=$ 8.18).

Three of these participants were also diagnosed with attention deficit disorder. All participants were frequent readers; per day, eleven read less than four hours per day, nine read between four and eight hours per day, and three participants read more than eight hours. ${ }^{10}$ Ten people were studying or already finished university degrees, eleven were attending school or high school, and two had no higher education.

A control group of 23 Spanish speakers (13 female, 10 male) without dyslexia also participated in the study (group N). Their ages ranged from 13 to 35 , with a mean age of 20.74 years $(s=8.18)$. That is, overall, we had 46 participants ( 25 female, 21 male).

\subsection{Materials}

To study the effects of word length and frequency, we need to study target words in context, that is, as part of a text. The rationale behind this is that readability and understandability pertain to longer segments of texts [19]. To isolate the effects of these variables, the texts need to be comparable in complexity. In this section, we describe how we designed the texts, the target words, and the questionnaires that were used in this study.

Base Texts. As basis for our tests, we picked four short texts with an average length of 60.63 words. For word-frequency, we used two texts about the consequences of wars in Pakistan and Somalia. These were the most similar pairs of texts we could find in the Spanish Simplex corpus [3]. For word-length, we created two mystery stories, one about a wizard and one about a car. In the following, we denote these texts with Pakistan, Somalia, Wizard, and Car.

To meet the comparability requirements among the texts belonging to the same experiment, we adapted the texts maintaining as much as possible the original text. We matched the readability of the texts by making sure that the parameters commonly used to compute readability [13], had the same or similar values:

\footnotetext{
${ }^{10}$ We think that the participants interpreted reading time as schooling time and that is why the numbers may seem exaggerated.
} 
(a) They have the same number of target words: Fifteen [ \pm frequent] word pairs for each of the texts in the word-frequency experiment and six [ \pm long] word pairs for each of the texts in the word-length experiment. Only in Somalia (wordfrequency experiment) two target words are repeated in the text.

(b) Within each experiment, the texts use the same genre, international news.

(c) They are about similar topics.

(d) They contain the same number of sentences: four sentences for each of the texts in the word-frequency experiment and three in the word-length experiment.

(e) The texts of each experiment have the same number of words per text (93 words for both texts in the word-frequency experiment and 33 words in the word-length experiment).

(f) All the texts have a similar word length, with an average length ranging from 4.89 to 5.50 letters.

(g) They contain the same number of unique named entities and they do not contain foreign words, numerical expressions or acronyms.

Text Layout. The presentation of the text has an effect on reading speed of people with dyslexia [18]. Therefore, we used a text layout that follows the recommendations of previous research. As font type, we chose Arial, sans serif, as recommended by Al Wabil et al. [1]. The text was left justified, as recommended by the British Association of Dyslexia [4]. Each line did not exceeded 62 characters/column, the font size was 20 point, and the colors used were black font with crème background, ${ }^{11}$ as recommended by Rello et al. [42].

Target Words. Word length and frequency were selected taking into consideration the problems that people with dyslexia encounter. To control that other dyslexicrelated difficulties did not interfere in the selected target words, we also took into account linguistic criteria during the selection of the target word pairs of synonyms:

(a) We did not include ambiguous names because they require more processing than unambiguous words [33].

(b) We did not change compound nouns or collocations in the texts. Instances like secretario general, 'secretary of state', which is composed by two tokens but one meaning, were discarded.

(c) We did not use irregular words, foreign words, non-words, and new words [9, $11]$.

(d) We took into consideration only common names. Uncommon names were discarded because they are more likely to be irregular, foreign, or new words.

(e) We did not take into consideration phonetically similar words, that is, homophonic words or pseudo homophonic words [31] and orthographically similar words [15].

To apply our criteria (a) to (d) we used linguistic knowledge using the Royal Spanish Academy Dictionary [34]. To control for orthographic and phonetic similarity (e)

11 The CYMK are crème (FAFAC8) and black (000000). Color difference: 700, Brightness difference: 244 [42]. 
of the target word, we consulted the database of indexes of frequency, length, and orthographic neighbours $^{12}$ in Spanish [32], which enables us to determine how many neighbours the target word has and how frequent are those neighbours. We can assume that orthographic and phonetic similarities are related in Spanish, because, as we mentioned before, it has a shallow orthography.

Word Frequency. For creating the pair of [ \pm frequent] synonyms we first extracted the nouns of the texts according to the previous selection criteria. Then, we checked their synonyms using a synonym dictionary ${ }^{13}$ and created a list of synonyms for each target word. We discarded nouns with no synonyms such as million or kilometer. We subsequently computed the relative frequencies of each of the synonyms for each of the lists using the advanced search of a major search engine. ${ }^{14}$ Then, we manually selected the pair of synonyms (most frequent and less frequent) for the context where the target noun occurred in the text. Each pair of [ \pm frequent] has a frequency difference of at least one order of magnitude, for instance morada, 'house', is 67 times less frequent than casa, 'house'. In the Appendix we present the pairs of synonyms with their frequency ratio. To maintain both factors independent, short nouns with less than four letters were discarded. Still, we could only partially control for length differences: the average length per word in the high frequency synonyms is 7.62 letters while for the low frequency synonyms is 9.56 letters.

Word Length. Finding synonym pairs with a relatively large difference in word length is challenging for Spanish because $79 \%$ of the words in the dictionary have between 6 and 11 letters. Note that the average word length in Spanish is 8.78 letters per lemma, being similar to English where is 8.99 letters. ${ }^{15}$

Therefore, for creating the pair of [ \pm long] synonyms we took all the Spanish lemmas from the Royal Spanish Academy Dictionary [34] and selected the longest words. Then, we looked up for the synonyms ${ }^{16}$ of these words to create the lists of synonyms. However, the majority of the longest words in Spanish do not have synonyms, for example electroencefalograma, 'electroencephalogra'. From the list of synonyms we selected synonym pairs where the [+long] synonym at least doubled the length of its [-long] counterpart. For instance apartamento, 'flat', is 2.75 times longer than piso, 'flat'. In the Appendix, we present the pairs of synonyms with their length ratio.

Comprehension Questionnaires. We used multiple-choice questions with three possible choices, one correct choice, one partially correct choice, and one wrong

12 Neighbours are all the words with the same length as the target word that differs in a single letter [10], that is, the Hamming distance between them is one. For instance, the word casa has many neighbours like masa, cosa, cama and caso.

13 http: //www. wordreference.com/sinonimos /

14 http://www.google.com/advanced_search

15 We used the Royal Spanish Academy Dictionary [34] and the Longman Dictionary of Contemporary English [28].

16 http: //www. wordreference.com/sinonimos/ 
choice. The questions were inferential, that is, answering it correctly required a deep understanding of the text content. An example question is given below:

(a) ¿De qué trata el texto? 'What is the text about?'.

a. Sobre la acción de la Cruz Roja en Somalia.

'About the Red Cross action in Somalia.'

b. Sobre las consecuencias de la guerra en la población de Somalia.

'About the consequences of the war on the Somalia population.'

c. Sobre el incremento del precio de los productos en Somalia.

'About the price increase of products in Somalia.'

\subsection{Equipment}

The eye tracker used was the Tobii T50 [48] that has a 17-inch TFT monitor with a resolution of $1024 \times 768$ pixels. The time measurements of the eye-tracker have a precision of 0.02 seconds. The eye tracker was calibrated for each participant and the light focus was always in the same position. The distance between the participant and the eye tracker was constant (approximately $60 \mathrm{~cm}$. or 24 in.) and controlled by using a fixed chair.

\subsection{Procedure}

The sessions were conducted at Universitat Pompeu Fabra and lasted from 30 to 40 minutes, depending on the amount of feedback given by the participant. In each session, the participant was alone with the interviewer in the quiet room prepared for the study, and performed the following three steps.

First, we began with a questionnaire that was designed to collect demographic information. Second, we conducted the two experiments, which were recorded using eye-tracking. Then, the participants were asked to read the texts in silence and to complete the comprehension tests after each completed text. Finally, we carried out a semi-structured interview, where we asked for feedback about the experiment and about the usefulness of lexical simplification.

\section{$5 \quad$ Results}

In this section we present the analyses of the data from the eye tracker (reading time and fixation duration) and the comprehension tests. First, we analyzed the differences among groups (D and $\mathrm{N}$ ) and then the effect of the conditions within each group.

The results are shown in Tables 1 and 2. A Shapiro-Wilk test showed that the three data sets were not normally distributed. However, a Barlett's test showed that they were homogeneous. Hence, we use Student's t-tests to show statistically significant effects. 
Table 1. Results of the word-frequency experiment

\begin{tabular}{|l||c|c|}
\hline \multirow{2}{*}{$\begin{array}{c}\text { Dependent Variable } \\
\text { (ave. } \pm \text { std.dev.) }\end{array}$} & \multicolumn{2}{|c|}{ Group D } \\
\cline { 2 - 3 } Reading Time (s) & $41.99 \pm 13.00$ & $53.35 \pm 19.10$ \\
Fixation Duration (s) & $0.22 \pm 0.04$ & $0.25 \pm 0.05$ \\
Comprehension Score & $90 \%$ & $87.5 \%$ \\
\hline \hline \multicolumn{2}{|c||}{ Group N } \\
\cline { 2 - 3 } Reading Time (s) & $24.17 \pm 6.18$ & $29.25 \pm 10.77$ \\
Fixation Duration (s) & $0.17 \pm 0.03$ & $0.18 \pm 0.03$ \\
Comprehension Score & $95 \%$ & $87.5 \%$ \\
\hline
\end{tabular}

Table 2. Results of the word-length experiment

\begin{tabular}{|l||c|c|}
\hline \multirow{2}{*}{$\begin{array}{c}\text { Dependent Variable } \\
\text { (ave. } \pm \text { std.dev.) }\end{array}$} & \multicolumn{2}{|c|}{ Group D } \\
\cline { 2 - 3 } Reading Time (s) & $21.23 \pm 10.28$ & $13.74 \pm 6.05$ \\
Fixation Duration (s) & $0.23 \pm 0.05$ & $0.22 \pm 0.04$ \\
Comprehension Score & $88.64 \%$ & $65.91 \%$ \\
\hline \hline & \multicolumn{2}{|c|}{ Group N } \\
\cline { 2 - 3 } Reading Time (s) & $11.78 \pm 4.24$ & $9.59 \pm 3.11$ \\
Fixation Duration (s) & $0.18 \pm 0.03$ & $0.17 \pm 0.03$ \\
Comprehension Score & $90.91 \%$ & $86.36 \%$ \\
\hline
\end{tabular}

Reading Time. We found a significant difference between the groups regarding reading time $(t(124.707)=5.434, p<0.001)$. Group D had significantly longer reading times $(\mu=31.86, s=20.28$ seconds) than the participants of group $\mathrm{N}(\mu=18.32, \mathrm{~s}=$ 10.53 seconds).

Word Frequency. For the participants with dyslexia we found a significant effect on reading time $(t(33.488)=-2.120, p=0.035)$. Using more frequent words lead to significantly shorter reading times $(\mu=41.99, s=13.00$ seconds) than using less frequent words ( $\mu=53.35, s=19.10$ seconds). For the control group we found no significant effect on reading time $(t(30.283)=-1.828, p=0.077)($ see Table 1$)$.

Word Length. For group D, we found a significant effect on reading time $(t(33.971)=$ $2.944, p=0.006)$. Using shorter words lead to significantly shorter reading times $(\mu=$ $13.74, s=6.05$ seconds) than using longer words $(\mu=21.23, s=10.28$ seconds $)$. For the control group, there was no significant effect on reading time $(t(38.569)=1.957, p$ $=0.058 \$$ ) (Table 2).

Fixation Duration. There was a significant difference between the groups regarding fixation duration $(t(140.111)=8.209, p<0.001)$. Participants with dyslexia had significantly longer fixation times $(\mu=0.23, s=0.05$ seconds $)$ than the participants without dyslexia ( $\mu=0.17, s=0.03$ seconds).

Word Frequency. For the participants with dyslexia, we found a significant effect on fixation duration $(t(35.741)=-2.150, p=0.038)$. Using more frequent words lead to 
significantly shorter fixation times $(\mu=0.22, s=0.04$ seconds) than using less frequent words $(\mu=0.25, s=0.05$ seconds). For the control group, no significant effect on fixation duration was found $(t(37.402)=-1.035, p=0.307)$ (see Table 1$)$.

Word Length. We found no significant effect on the fixation duration in group D $(t(40.002)=0.763, p=0.450)$, nor in group $\mathrm{N}(t(41.526)=0.991, p=0.327) \quad($ see Table 2).

Comprehension Score. Participants with dyslexia answered fewer questions correctly $(\mu=82.74 \%, s=28.51 \%)$ than participants without dyslexia $(\mu=89.88 \%, s=$ $20.21 \%)$. However, the difference between the groups was not statistically significant $(t(149.593)=-1.873, p=0.063))$.

Word Frequency. We did not found a significant effect on text comprehension for group $\mathrm{D}(t(37.764)=0.370, p=0.714)$ nor for group $\mathrm{N}(t(33.824)=1.241, p=0.223)$ (see Table 1).

Word Length. For the participants with dyslexia, we found a significant effect on the comprehension score $(t(38.636)=-2.396, p=0.022)$. Shorter words led to significantly higher text comprehension $(\mu=88.64 \%, s=26.42 \%)$ than longer words $(\mu=$ $65.91 \%, s=35.81 \%$ ). For the control group, changing the word length had no significant effect on text comprehension $(t(41.16)=-0.707, p=0.484)$ (see Table 2).

\section{Discussion}

In general, participants without dyslexia read significantly faster and had shorter fixation durations than participants with dyslexia. However, participants with dyslexia read significantly faster and have significantly shorter fixation durations using more frequent words. Using shorter words caused participants with dyslexia to read significantly faster and significantly increased their text comprehension. For the people without dyslexia, no differences in reading time, fixation duration, or text comprehension were found.

Regarding the differences between the groups, our results are consistent with other eye-tracking studies to diagnose dyslexia that found statistical differences between the two populations [14].

Since shorter reading times and fixation durations are associated with better readability, our findings support H1.1 A larger number of high frequency words increases readability for people with dyslexia. The effect of frequency is more pronounced in people with dyslexia than in people without dyslexia, where non significant results were found. Our results are consistent with previous results for both groups. Word frequency was found to have a powerful influence on word recognition tasks for people with [20] or without [33, 44] dyslexia and some reading experiments have demonstrated that readers spend more time looking at low-frequency words than at high-frequency words [20].

In Figure 1 we consider the two visual behaviors that we use as surrogate variables for readability (reading time and fixation duration), visualizing the distribution of the 
data in such 2D space. A more meaningful feature emerges that can be obtained from a linear combination of both of them. ${ }^{17}$ The emerging feature can be interpreted as a readability variable that defines the readability axis. Thus, any readability improvement that moves along the direction determined by the arrow approaches the "ideal situation", which is characterized by target values reached by people without dyslexia in the most favorable conditions (e.g. the behavior on people without dyslexia in texts with higher frequency words). The use of more frequent words bring the average fixation time of group D closer to group N.

Since word frequency had no significant effect on text comprehension, we cannot confirm H1.2: A larger number of high frequency words increases understandability for people with dyslexia.

Since shorter reading times are associated with better readability, our findings support H2.1: The presence of short words compared to long words increases readability for people with dyslexia. Although no statistical significance has been found for length regarding fixation duration, we can observe a qualitative improvement in the readability through the use of shorter words since the mean fixation duration for group $\mathrm{D}$ also comes closer to the mean fixation duration for group $\mathrm{N}$.

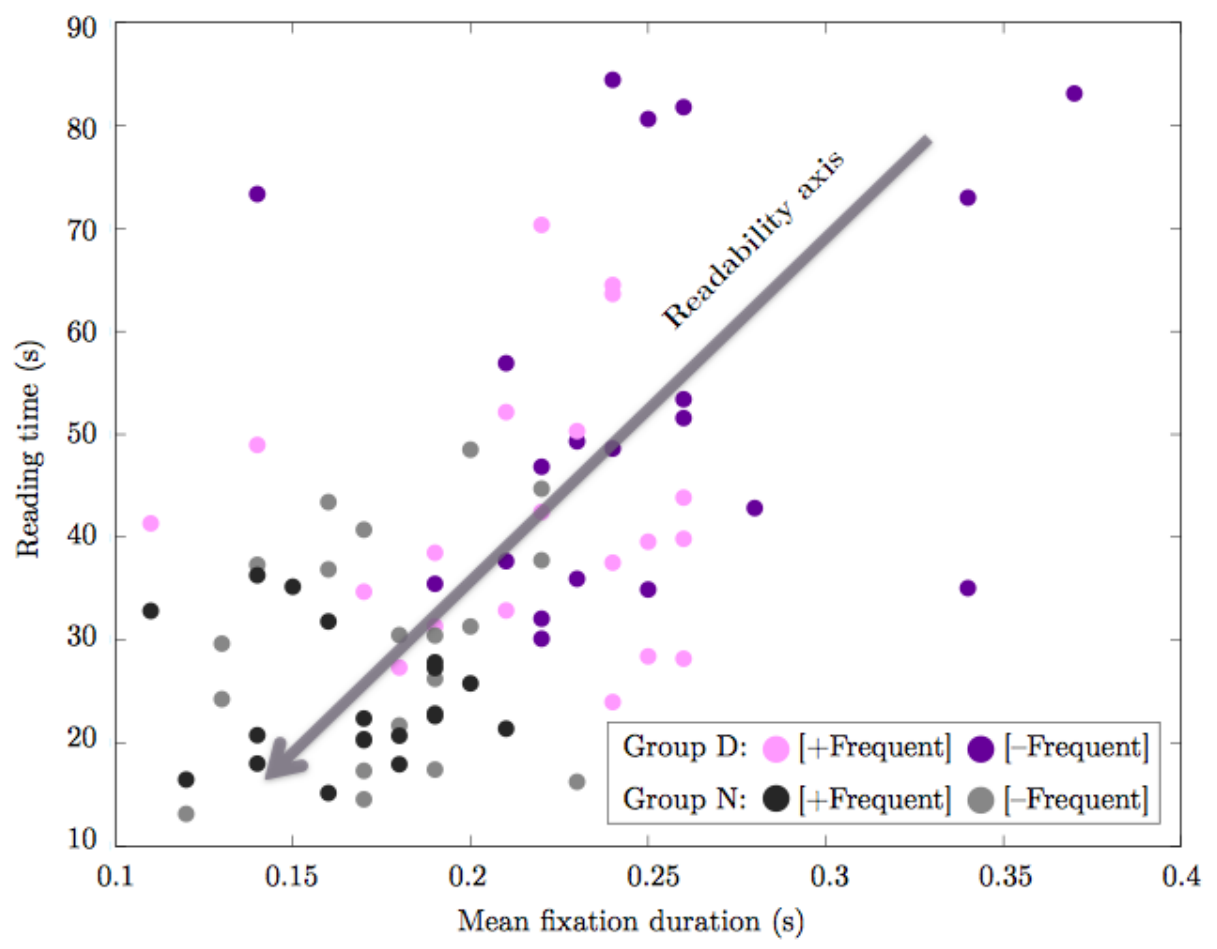

Fig. 1. Readability as a function of reading time and fixation duration

17 Doing a least squares linear regression we obtain the formula Reading time $=173.3 \times$ Fixation time +2.2 seconds (Pearson correlation of 0.51 and $p<0.001$ ). 
One possible explanation of the lower significance of word length than word frequency is that Wizard might have been more difficult to read than Car. According to some of the comments of the participants during the open questions, the fact that there was an additive set in front of the noun in the text Wizard made it a bit more complicated for further reading. In Spanish, adjectives postponed to nouns are frequent and natural (unmarked syntactic structure for most of the cases), therefore this might be a new variable to take into consideration in further work.

Because participants with dyslexia had a significantly increased text comprehension with texts having shorter words, our findings support H2.2: The presence of short words compared to long words increases understandability for people with dyslexia.

One of the limitations of our study is that the inferences made from H2.1 and H2.2 could be due to the low frequency of long words and not to their length. Through the experimental design we maintained as much as possible both factors - frequency and length - separated for studying both effects independently. However a total dissociation was not possible, as we could not find long words that were more frequent than their shorter synonyms. Although Rayner and Duffy [33] explain the necessity to study both effects separately, such separation between token frequency of linguistic expressions and their length does not exist in natural language [6]. Words [+long] are in average 59.45 less frequent than their correspondent [-long] synonyms. However this frequency ratio is not as high as in the experiment word frequency where [+frequent] were 1249.17 times more frequent in average than their [-frequent] synonyms (see Appendix for the frequency ratios for each pair). Since using shorter words usually implies more frequent words, H1.1 and H2.1 reinforce each other.

However, the reasons why longer and less frequent words receive longer fixations are different [20], because while less frequent words require more processing, the word-length effect can be ascribed to acuity limitations of the visual system. ${ }^{18}$ On the other hand, longer words may imply more fixations instead of longer fixations.

\section{$7 \quad$ Conclusions and Future Work}

We tested the effect of word length and frequency on readability and comprehension. Our results show that more frequent words improve readability while shorter words may improve understandability, especially in people with dyslexia. The results also provide evidence about the potential of measuring fixation duration and reading time as a visual behavior surrogate for the readability of a text. The results suggest that people without dyslexia come closer to the ideal reading scenario with shorter fixations and reading time as well as better text comprehension.

These findings can have great impact on interactive systems that rely on text as the main information medium, such as browsers, PDF viewers, or eBook readers. By applying our suggested lexical simplification strategies, namely substituting long and non-frequent words through shorter and frequent synonyms, these systems could

18 Long words extend beyond the fovea where the acuity is greatest, thus increasing the need for making a fixation and even a re-fixation on a word [20]. 
make texts easier to read and understand for people with dyslexia. We implemented an automatic method for lexical simplification in Spanish [2] and tried two different interactive strategies with participants with dyslexia [37]. We found that showing simpler synonyms on demand had a better impact than substituting such synonyms. Further improvements on the user interactions are being done and final results will be integrated in DysWebxia 2.0 [38], a tool that modifies text content and layout for people with dyslexia.

Since there is a correlation between word length and frequency, as frequently used words tend to be shorter, future work needs to investigate potential inter-dependencies between these two factors. We will explore also to what extent lexical simplifications can improve the readability of texts that people with dyslexia read as part of their daily life, such as news, Facebook entries, or Wikipedia articles.

Acknowledgments. We thank Maarten Janssen for facilitating us the dictionary entries and Giorgio Brajnik for his invaluable comments and advise. We thank MariCarmen Marcos for her assistance with the eye-tracker hardware and Joaquim Llisterri for his help distributing our experiments announcement among experts. This research was funded by the Spanish Ministry of Education and Science (Grant TIN2009-14560-C03-01) and the FI Catalonian scholarship program.

\section{References}

1. Al-Wabil, A., Zaphiris, P., Wilson, S.: Web navigation for individuals with dyslexia: An exploratory study. In: Stephanidis, C. (ed.) HCI 2007. LNCS, vol. 4554, pp. 593-602. Springer, Heidelberg (2007)

2. Bott, S., Rello, L., Drndarevic, B., Saggion, H.: Can Spanish be simpler? LexSiS: Lexical simplification for Spanish. In: Proc. Coling 2012, Mumbay, India (December 2012)

3. Bott, S., Saggion, H.: Text simplification tools for Spanish. In: Proceedings of the Eighth International Conference on Language Resources and Evaluation, LREC 2012, Istanbul, Turkey (May 2012)

4. British Dyslexia Association. Dyslexia style guide (January 2012), http: / / www . bdadyslexia.org.uk/

5. Brunswick, N.: Unimpaired reading development and dyslexia across different languages. In: McDougall, S., de Mornay Davies, P. (eds.) Reading and Dyslexia in Different Orthographies, pp. 131-154. Psychology Press, Hove (2010)

6. Bybee, J.: Phonology and language use, vol. 94. Cambridge Univ. Press (2003)

7. Carrillo, M.S., Alegría, J., Miranda, P., Pérez, S.: Evaluación de la dislexia en la escuela primaria: Prevalencia en español (Evaluation of dyslexia in primary school: The prevalence in Spanish). Escritos de Psicología 4(2), 35-44 (2011)

8. ClaroSoftware (2012), http: / / www . clarosoftware.com/index . php?cPath=348

9. Coltheart, M.: Phonological dyslexia: Past and future issues. Cognitive Neuropsychology 13(6), 749-762 (1996)

10. Coltheart, M., Davelaar, E., Jonasson, T., Besner, D.: Access to the internal lexicon. In: Attention and Performance VI, pp. 535-555 (1977) 
11. Cuetos, F., Valle, F.: Modelos de lectura y dislexias (Reading models and dyslexia). Infancia y Aprendizaje (Infancy and Learning) 44, 3-19 (1988)

12. Dixon, M.: Comparative study of disabled vs. Non-disabled evaluators in user-testing: Dyslexia and first year students learning computer programming. In: Stephanidis, C. (ed.) HCI 2007. LNCS, vol. 4554, pp. 647-656. Springer, Heidelberg (2007)

13. Drndarevic, B., Saggion, H.: Towards automatic lexical simplification in Spanish: an empirical study. In: Proc. NAACL HLT 2012 Workshop PITR 2012 (2012)

14. Eden, G., Stein, J., Wood, H., Wood, F.: Differences in eye movements and reading problems in dyslexic and normal children. Vision Research 34(10), 1345-1358 (1994)

15. Ellis, A.: Reading, writing and dyslexia. Erlbaum, London (1984)

16. Evett, L., Brown, D.: Text formats and web design for visually impaired and dyslexic readers-clear text for all. Interacting with Computers 17, 453-472 (2005)

17. Gregor, P., Dickinson, A., Macaffer, A., Andreasen, P.: Seeword: a personal word processing environment for dyslexic computer users. British Journal of Educational Technology 34(3), 341-355 (2003)

18. Gregor, P., Newell, A.F.: An empirical investigation of ways in which some of the problems encountered by some dyslexics may be alleviated using computer techniques. In: Proceedings of the Fourth International ACM Conference on Assistive Technologies, ASSETS 2000, New York, NY, USA, pp. 85-91 (2000)

19. Huenerfauth, M., Feng, L., Elhadad, N.: Comparing evaluation techniques for text readability software for adults with intellectual disabilities. In: Proc. ASSETS 2009, pp. 3-10. ACM (2009)

20. Hyönä, J., Olson, R.: Eye fixation patterns among dyslexic and normal readers: Effects of word length and word frequency. Journal of Experimental Psychology: Learning, Memory, and Cognition 21(6), 1430 (1995)

21. Interagency Commission on Learning Disabilities. Learning Disabilities: A Report to the U.S. Congress. Government Printing Office, Washington DC, U.S. (1987)

22. International Dyslexia Association. Definition of dyslexia (2011), http://interdys.org/DyslexiaDefinition.htm; Based in the initial definition of the Research Committee of the Orton Dyslexia Society, former name of the IDA, done in 1994

23. Jiménez, J.E., Guzmán, R., Rodríguez, C., Artiles, C.: Prevalencia de las dificultades específicas de aprendizaje: La dislexia en español (The prevalence of specific learning difficulties: Dyslexia in Spanish). Anales de Psicología (Annals of Psychology) 25(1), 78-85 (2009)

24. Jurafsky, D., Bell, A., Gregory, M., Raymond, W.: Evidence from reduction in lexical production. Frequency and the Emergence of Linguistic Structure 45, 229 (2001)

25. Just, M., Carpenter, P.: A theory of reading: From eye fixations to comprehension. Psychological Review 87, 329-354 (1980)

26. Kanvinde, G., Rello, L., Baeza-Yates, R.: IDEAL: a dyslexic-friendly e-book reader (poster). In: Proc. ASSETS 2012, Boulder, USA. ACM Press (October 2012)

27. Lachmann, T., Van Leeuwen, C.: Different letter-processing strategies in diagnostic subgroups of developmental dyslexia. Cognitive Neuropsychology 25(5), 730-744 (2008)

28. Longman, P.: Longman dictionary of contemporary English. Pearson Longman (2009)

29. McCarthy, J.E., Swierenga, S.J.: What we know about dyslexia and web accessibility: a research review. Universal Access in the Information Society 9, 147-152 (2010)

30. Nation, K., Snowling, M.: Individual differences in contextual facilitation: Evidence from dyslexia and poor reading comprehension. Child Development 69(4), 996-1011 (1998) 
31. Patterson, K., Marshall, J., Coltheart, M.: Surface dyslexia: Neuropsychological and cognitive studies of phonological reading. Lawrence Erlbaum Associates, London (1985)

32. Pérez, M., Alameda Bailén, J., Cuetos Vega, F.: Frecuencia, longitud y vecindad ortográfica de las palabras de 3 a 16 letras del diccionario de la lengua española (Frequency, length and orthographical neighborhood of the words from 3 to 16 letters of the dictionary of the Spanish language - RAE 1992). REMA: Revista Electrónica de Metodología Aplicada (Electronic Journal of Applied Methodology) 8(2), 1-10 (2003)

33. Rayner, K., Duffy, S.: Lexical complexity and fixation times in reading: Effects of word frequency, verb complexity, and lexical ambiguity. Memory \& Cognition 14(3), 191-201 (1986)

34. Real Academia Española. Diccionario de la lengua española (Dictionary of the Spanish language). Espasa-Calpe, Madrid, 22nd edn (2001)

35. Rello, L., Baeza-Yates, R.: Lexical quality as a proxy for web text understandability (poster). In: Proc. WWW 2012, Lyon, France (2012)

36. Rello, L., Baeza-Yates, R.: The presence of English and Spanish dyslexia in the Web. New Review of Hypermedia and Multimedia 8, 131-158 (2012)

37. Rello, L., Baeza-Yates, R., Bott, S., Saggion, H.: Simplify or help? Text simplification strategies for people with dyslexia. In: Proc. W4A 2013, Rio de Janeiro, Brazil (2013)

38. Rello, L., Baeza-Yates, R., Saggion, H., Bott, S., Carlini, R., Bayarri, C., Gòrriz, A., Gupta, S., Kanvinde, G., Topac, V.: Dyswebxia 2.0!: Accessible text for people with dyslexia (demo). In: Proc. W4A 2013, The Paciello Group Web Accessibility Challenge, Rio de Janeiro, Brazil (2013)

39. Rello, L., Baeza-Yates, R., Saggion, H., Graells, E.: Graphical schemes may improve readability but not understandability for people with dyslexia. In: Proceedings of the NAACL HLT 2012 Workshop Predicting and Improving Text Readability for Target Reader Populations, PITR 2012 (2012)

40. Rello, L., Bautista, S., Baeza-Yates, R., Gervás, P., Hervás, R., Saggion, H.: One half or $50 \%$ ? An eye-tracking study of number representation readability. In: Kotzé, P., Marsden, G., Lindgaard, G., Wesson, J., Winckler, M. (eds.) INTERACT 2013, Part IV. LNCS, vol. 8120, pp. 229-245. Springer, Heidelberg (2013)

41. Rello, L., Bayarri, C., Gorriz, A.: What is wrong with this word? Dyseggxia: a game for children with dyslexia (demo). In: Proc. ASSETS 2012, Boulder, USA. ACM Press (October 2012)

42. Rello, L., Kanvinde, G., Baeza-Yates, R.: Layout guidelines for web text and a web service to improve accessibility for dyslexics. In: Proc. W4A 2012, Lyon, France. ACM Press (2012)

43. Rüsseler, J., Probst, S., Johannes, S., Münte, T.: Recognition memory for high-and lowfrequency words in adult normal and dyslexic readers: an event-related brain potential study. Journal of Clinical and Experimental Neuropsychology 25(6), 815-829 (2003)

44. Sereno, S., Rayner, K.: Measuring word recognition in reading: eye movements and eventrelated potentials. Trends in Cognitive Sciences 7(11), 489-493 (2003)

45. Seymour, P., Aro, M., Erskine, J.: Foundation literacy acquisition in European orthographies. British Journal of Psychology 94(2), 143-174 (2003)

46. Simmons, F., Singleton, C.: The reading comprehension abilities of dyslexic students in higher education. Dyslexia 6(3), 178-192 (2000)

47. Stanley, G., Smith, G., Howell, E.: Eye-movements and sequential tracking in dyslexic and control children. British Journal of Psychology 74(2), 181-187 (1983)

48. Tobii Technology. Product description Tobii 50 Series (2005)

49. Topac, V.: The development of a text customization tool for existing web sites. In: Text Customization for Readability Symposium (November 2012) 
50. Vellutino, F., Fletcher, J., Snowling, M., Scanlon, D.: Specific reading disability (dyslexia): What have we learned in the past four decades? Journal of Child Psychology and Psychiatry $45(1), 2-40$ (2004)

51. Williams, S., Reiter, E., Osman, L.: Experiments with discourse-level choices and readability. In: Proc. ENLG 2003, Budapest, Hungary (2003)

52. Wimmer, H.: Characteristics of developmental dyslexia in a regular writing system. Applied Psycholinguistics 14(1) (1993)

\section{Appendix: Synonyms Pairs}

The list of the unique pairs of synonyms used in the experiment word-frequency is below. The frequency ratio appears in parenthesis after the [ \pm frequent].

\begin{tabular}{|c|c|c|c|}
\hline \multicolumn{2}{|c|}{$\begin{array}{l}\text { Pakistan } \\
{[+ \text { frequent }][- \text { frequent }]}\end{array}$} & $\begin{array}{l}\text { Somalia } \\
{[+ \text { frequent }]}\end{array}$ & [-frequent $]$ \\
\hline ataques & refriegas (474) & personas & individuos (26) \\
\hline sequía & agostamiento (903) & casas & moradas (173) \\
\hline entrega & avituallamiento (787) & inundaciones & aluviones (123) \\
\hline casa & morada (67) & lluvias & diluvios (195) \\
\hline personas & individuos (26.3) & verano & canícula $(21,140)$ \\
\hline ciudades & urbes (106) & desastre & hecatombe (31) \\
\hline ejército & hueste (209) & parte & porción (58) \\
\hline rebeldes & insubordinados (511) & país & territorio (6) \\
\hline ciudad & capitalidad (484) & estado & tesitura (741) \\
\hline producción & obtención (39) & comunidad & colectividad (89) \\
\hline alimentos & sustentos (968) & generosidad & dadivosidad (285) \\
\hline precios & valías $(5,897)$ & velocidad & apresuramiento (491) \\
\hline gente & muchedumbre (107) & necesidades & indigencias (19) \\
\hline productos & manufacturas (133) & & \\
\hline
\end{tabular}

The list of the unique pairs of synonyms used in the experiment word-length is shown below. The frequency ratio appears in parenthesis after the [+long] word. The length ratio is shown after the frequency ratio.

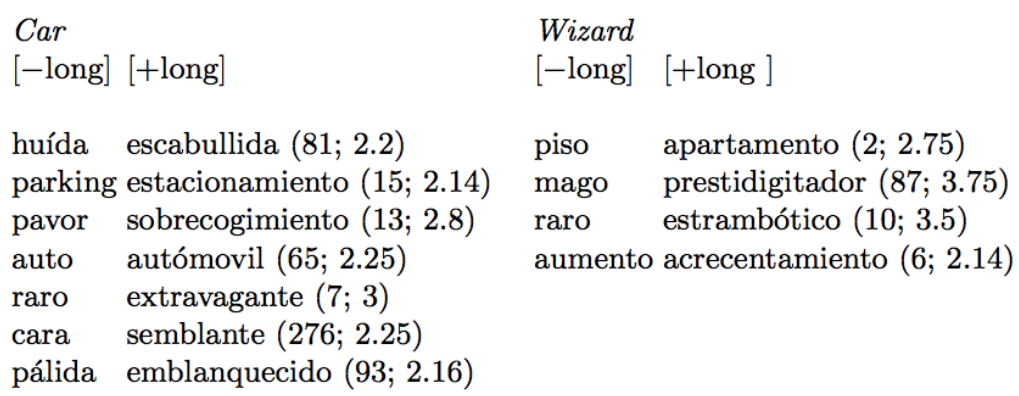

